\title{
TRATAMENTO DE SOLUÇÃO AQUOSA CONTAMINADA COM ÍONS FLUORETO VIA ADSORÇÃO
}

\author{
R. R. A. CRUZ ${ }^{1 *}$, L. MEILI' ${ }^{1}$, J. I. SOLETTI ${ }^{1}$, S. H. V. CARVALHO ${ }^{1}$ \\ Universidade Federal de Alagoas, Centro de Tecnologia \\ e-mail: rodolforodrigocruz@ hotmail.com
}

\begin{abstract}
RESUMO
O presente trabalho teve como objetivo estudar e desenvolver uma tecnologia que possibilite remover fluoreto de águas de abastecimento. Como, cada vez mais, perfuram-se poços mais profundos, mais contaminantes são encontrados, e o fluoreto é um destes. Se este íon estiver em excesso na água de consumo pode ser prejudicial à população que a consumir, causando uma série de doenças, como a fluorose dentária, e apesar de várias tentativas e tecnologias de remoção terem sido testadas, nenhuma se mostra completamente eficiente e eficaz nesta. Neste sentido, vários adsorventes vêm sendo estudados para remover este contaminante e determinar uma tecnologia barata e segura, dois deles são o carvão ativado vegetal e o carvão de ossos calcinados, que são os estudados neste trabalho. O estudo foi conduzido analisando, em batelada, alguns parâmetros que poderiam interferir no poder adsortivo, a presença de outros contaminantes, o pH e a temperatura, além da comparação entre o carvão de ossos calcinados e o carvão vegetal. Deste trabalho foi possível concluir que existe uma relação bem evidenciada entre as variáveis estudadas e o poder de adsorção dos materiais avaliados.
\end{abstract}

\section{INTRODUÇÃO}

Com a crescente demanda por água potável somada à escassez cada vez mais acentuada no planeta, novas formas de captação vêm sendo estudadas e até mesmo exploradas. Grandes poços e aquíferos, cada vez mais profundos, vêm sendo escavados com o objetivo de captação de águas de boa qualidade para consumo.

Apesar dos esforços em encontrar poços com a qualidade da água apreciável, a ocorrência de contaminações dos mais diversos tipos é recorrente e cada vez mais presente. Quando não se tem contaminações organolépticas, há contaminações iônicas que, podem vir a causar sérios danos à saúde humana e fogem aos limites impostos pela Portaria do Ministério da Saúde n 2914 de 12 de dezembro de 2011, do Ministério da Saúde (BRASIL, 2011). Uma dessas contaminações pode ser a partir do íon fluoreto.

É conhecido o poder do fluoreto no combate às cáries dentárias, porém em doses pequenas e calculadas, esta propriedade garante a utilização deste ânion em diversas localidades no mundo. No Brasil, por exemplo, a fluoretação da água é bastante utilizada para prevenir as cáries. (CHARBEL, 1990)

Segundo Umlong et al. (2012), por outro lado, o excesso da concentração deste elemento pode causar a fluorose dentária, que é uma anomalia na qual a estética do esmalte 
dentário é seriamente prejudicada. Esta consequência é alcançada se um indivíduo for exposto a concentrações maiores que 1,5 $\mathrm{mg} / \mathrm{L}$ de fluoreto sob um demasiado tempo. A depender do tempo de exposição e concentração, podem se desenvolver linhas brancas no dente até um grande desgaste dos dentes. Além desta doença, outras complicações podem ser frequentes em indivíduos que consomem águas com excesso de fluoreto como úlceras gástricas, cistite, enxaqueca e má formação do feto.

O flúor é o íon mais eletronegativo e em solução aquosa forma íons fluoreto. Em sistemas naturais, o flúor não é encontrado em outros níveis de oxidação, portanto, para saber qual o nível de contaminação por parte do flúor em um sistema aquoso natural, devese mensurar a concentração de íons fluoreto (TAKENO, 2005).

Segundo Saxena e Ahmed (2001), este processo de deposição e dissociação do flúor em água decorre sob condições físicoquímicas favoráveis e quando há um tempo longo de contato entre o mineral e a água. Outros fatores também são determinantes para a dissociação do flúor em água, como baixa dureza, presença de materiais trocadores de íons e na presença de cálcio e magnésio, além de condições ácidas (PICKERING, SLAVEK e WALLER, 1988; SAHU e KARIM, 1989).

Para o tratamento das águas com contaminação por íons fluoreto, várias tecnologias são conhecidas, dentre as mais aplicadas tem-se a troca iônica, a coagulaçãoprecipitação, separação por membranas e adsorção. Este último método, vem garantindo um lugar de destaque entre as demais e cada vez mais estudos vêm sendo realizados para garantir melhoras ao processo e garantir maior eficiência de remoção.

Eventualmente, o carvão de ossos calcinados é utilizado na remoção de cor na indústria açucareira, porém tem despertado grande interesse em diversas aplicações no tratamento de águas contaminadas com compostos tanto orgânicos quanto inorgânicos (RIBEIRO et al., 2011). O carvão pode ser produzido pela calcinação dos ossos secos e moídos a $800^{\circ} \mathrm{C}$ em atmosfera com concentração limitada de oxigênio. Os carvões ativados convencionais apresentam majoritariamente carbono, ao passo que o carvão de ossos calcinados apresenta somente cerca de $10 \%$ em massa de carbono e já despertou a atenção de vários pesquisadores. A maior parte é principalmente hidroxiapatita e quantidades menores de $\mathrm{CaCO}_{3}$ são comumente encontradas, o que confere uma característica alcalina, tornando-o bastante interessante para a aplicação em tratamento de efluentes ácidos (ALESSIO, 2014).

Cientistas como Tchomgui-Kamga, Ngameni e Darchen (2010); Costa et al. (2013); Abe et al. (2004) estudaram a desfluoretação de afluentes através da adsorção em carvão de ossos calcinados, porém, para que haja uma utilização industrial eficaz, se fazem necessárias mais estudos, principalmente nos aspectos operacionais como a cinética e os mecanismos de remoção. Ao reconhecer-se tais parâmetros, será mais simples e seguro o dimensionamento de equipamentos industriais e destinação do agente adsorvente utilizado após não se conseguir mais a sua recuperação.

\section{OBJETIVOS}

Verificar a eficiência do carvão vegetal ativado e do carvão de ossos calcinados como adsorventes no processo de desfluoretação de soluções aquosas, em presença de nitrato e sulfato para consumo humano e industrial, submetendo a solução a variação de $\mathrm{pH}$ e de temperatura. 


\section{MATERIAIS E MÉTODOS}

2.1 Determinação da Influência do Sulfato e Nitrato e Comparação Entre Carvão de Ossos e Carvão Ativado no Processo por Batelada.

Inicialmente, analisou-se o comportamento da adsorção do fluoreto em batelada. Estudando a diferença no poder de adsorção do carvão ativado vegetal (8 a 30 mesh) da empresa Carbonmar e o carvão de ossos calcinados (8 a 24 mesh) da empresa Bonechar

Nesta etapa dos experimentos, preparou-se quatro soluções com as seguintes características:

A) Solução contaminada com íons fluoreto $(2 \mathrm{mg} / \mathrm{L})$;

B) Solução contaminada com íons fluoreto $(2 \mathrm{mg} / \mathrm{L})$ e íons nitrato $(10$ $\mathrm{mg} / \mathrm{L})$;

C) Solução contaminada com íons fluoreto $(2 \mathrm{mg} / \mathrm{L})$ e íons sulfato $(10$ $\mathrm{mg} / \mathrm{L})$;
D) Solução contaminada com íons fluoreto $(2 \mathrm{mg} / \mathrm{L})$, íons nitrato (10 $\mathrm{mg} / \mathrm{L})$ e íons sulfato (10 mg/L).

Preparada as soluções, adicionou-se em $200 \mathrm{~mL}$ de cada amostra 0,5 gramas de carvão ativado vegetal Carbonmar e se manteve sob agitação magnética durante 20 minutos, mensurando o $\mathrm{pH}$ e a temperatura à qual se encontrava a água. Ao término do tempo, coletou-se uma amostra e analisou-se o teor de fluoreto de cada solução no equipamento Hanna HI 83208 (colorimetria), este equipamento foi utilizado em todos os experimentos do presente trabalho.

Repetiu-se os mesmos procedimentos, porém com a utilização de carvão de ossos calcinados da Bonechar para comparação entre a eficiência dos dois materiais adsortivos.

As características das amostras para análises do tipo de carvão e influência de ânions podem ser vistas na tabela 1 .

Tabela 1: Características das amostras para as análises do tipo de carvão e influência de ânions.

\begin{tabular}{|c|c|c|c|c|c|c|c|}
\hline Solução & $\begin{array}{c}\text { Volume } \\
(\mathbf{m L})\end{array}$ & $\begin{array}{c}\text { Concentração } \\
\mathbf{d e} \text { fluoreto } \\
(\mathbf{m g} / \mathbf{L})\end{array}$ & $\begin{array}{c}\text { Massa } \\
\mathbf{d e} \\
\text { carvão } \\
(\mathbf{g})\end{array}$ & $\begin{array}{c}\text { Tempo } \\
\mathbf{d e} \\
\text { contato } \\
(\mathbf{m i n})\end{array}$ & $\mathbf{p H}$ & $\begin{array}{c}\text { Temperatura } \\
\left({ }^{\circ} \mathbf{C}\right)\end{array}$ & $\begin{array}{c}\text { Massa de } \\
\text { fluoreto na } \\
\text { amostra } \\
(\mathbf{m g})\end{array}$ \\
\hline $\mathrm{A}$ & 200 & 1,97 & 0,5 & 20 & 3 & 23 & 0,394 \\
\hline $\mathrm{B}$ & 200 & 1,96 & 0,5 & 20 & 3 & 23 & 0,392 \\
\hline $\mathrm{C}$ & 200 & 1,98 & 0,5 & 20 & 3 & 23 & 0,396 \\
\hline $\mathrm{D}$ & 200 & 1,95 & 0,5 & 20 & 3 & 23 & 0,39 \\
\hline
\end{tabular}

Fonte: Acervo do autor (2015).

A característica ácida da amostra é evidenciada pelo fato das soluções serem preparadas a partir de ácido fluorídrico. A temperatura foi a ambiente.

\subsection{Avaliação da Influência do pH.}

Com a determinação de que o nitrato e o sulfato não diminuíam o poder adsortivo e que o carvão de ossos traz maior eficiência, realizou-se um novo experimento adicionando hidróxido de sódio à solução "A" variando o $\mathrm{pH}$ e configurando três novas soluções:

E) Solução contaminada com íons fluoreto (2 mg/L); $\mathrm{pH}=4$;

F) Solução contaminada com íons fluoreto ( $2 \mathrm{mg} / \mathrm{L}) ; \mathrm{pH}=7,3$;

G) Solução contaminada com íons fluoreto $(2 \mathrm{mg} / \mathrm{L}) ; \mathrm{pH}=10,3$. 
Submeteu-se $200 \mathrm{~mL}$ de amostra à 0,5 gramas de carvão de ossos calcinados e manteve-se sob agitação magnética durante

\subsection{Avaliação da Influência da Temperatura.}

Com a avaliação da influência do $\mathrm{pH}$, foi realizado novos experimentos para a verificação da influência da temperatura, para isso foram feitos as seguintes soluções:

H) Solução contaminada com íons fluoreto $(2 \mathrm{mg} / \mathrm{L}) ; \mathrm{pH}=4$; Temperatura $=$ $20{ }^{\circ} \mathrm{C}$;

I) Solução contaminada com íons fluoreto $(2 \mathrm{mg} / \mathrm{L}) ; \mathrm{pH}=4$; Temperatura $=30{ }^{\circ} \mathrm{C}$;

J) Solução contaminada com íons fluoreto $(2 \mathrm{mg} / \mathrm{L}) ; \mathrm{pH}=4$; Temperatura $=50{ }^{\circ} \mathrm{C}$;

Manteve-se, novamente em contato com o carvão de ossos calcinados e em agitação magnética durante 20 minutos e regulou-se a temperatura através de aquecedores. Coletou-se amostras das alíquotas e as analisamos.
20 minutos sob temperatura ambiente. Ao final, coletou-se amostras das três alíquotas e analisou-se a concentração final de fluoretos.

\section{RESULTADOS E DISCUSSÕES}

\subsection{Determinação da Influência do Sulfato e Nitrato e Comparação Entre Carvão de Ossos e Carvão Ativado no Processo por Batelada.}

A avaliação da influência de outros ânions no processo de adsorção de íons fluoreto é muito importante para a validação do sistema. Esta importância se dá pela interferência de outros ânions como o nitrato e o sulfato em outros processos conhecidos, como a troca iônica.

Além disto, outro parâmetro analisado neste tópico é a comparação entre a eficiência na adsorção do carvão ativado vegetal e a do carvão de ossos calcinados. Esta análise determinou qual o melhor carvão a ser utilizado no restante dos experimentos. após tempo de contato com o carvão ativado vegetal podem ser vistas na tabela 2 .

Tabela 2: Características das amostras após tempo de contato com o carvão ativado vegetal.

\begin{tabular}{|c|c|c|c|c|}
\hline Solução & $\begin{array}{c}\text { Concentração } \\
\text { de fluoretos } \\
(\mathbf{m g} / \mathbf{L})\end{array}$ & $\begin{array}{c}\text { Quantidade } \\
\text { mássica de } \\
\text { fluoreto na } \\
\text { amostra (mg) }\end{array}$ & $\begin{array}{c}\text { Capacidade adsortiva do } \\
\text { carvão ativado vegetal } \\
\text { (mg fluoreto/g de carvão) }\end{array}$ & $\begin{array}{c}\text { Porcentagem } \\
\text { de remoção } \\
(\%)\end{array}$ \\
\hline A & 1,78 & 0,356 & 0,076 & 9,64 \\
\hline B & 1,77 & 0,354 & 0,076 & 9,69 \\
\hline C & 1,77 & 0,354 & 0,084 & 10,61 \\
\hline D & 1,78 & 0,356 & 0,068 & 8,72 \\
\hline
\end{tabular}

Fonte: Acervo do autor (2015).

Ao analisar a tabela 2 pode-se verificar que as soluções com aditivos de nitrato e/ou sulfato não interferiram na adsorção do fluoreto, ou seja, a princípio, os dois ânions que interferem em outros processos de remoção de íons fluoreto não influenciam no processo adsortivo do fluoreto no carvão ativado vegetal, ao contrário a presença destes íons favorece o processo.

A adsorção não teve altos valores de remoção, chegou ao máximo de $10,61 \%$ na amostra "C", isto pode ser explicado pela alta 
instabilidade do íon fluoreto, que em contato com o carvão, é adsorvido e dessorvido simultaneamente. Esta característica nos impõe um novo desafio no presente trabalho: avaliar um tempo de contato tal que garanta a maior capacidade de adsorção de íons fluoreto sem que não ocorra uma dessorção simultânea e consequentemente uma nova contaminação do afluente.

As características das amostras após tempo de contato com o carvão de ossos calcinados estão dispostas na tabela 3 .

Tabela 3: Características das amostras após tempo de contato com o carvão de ossos calcinados.

\begin{tabular}{|c|c|c|c|c|}
\hline Solução & $\begin{array}{c}\text { Concentração } \\
\text { de fluoretos } \\
\text { (mg/L) }\end{array}$ & $\begin{array}{c}\text { Quantidade } \\
\text { mássica de } \\
\text { fluoreto na } \\
\text { amostra (mg) }\end{array}$ & $\begin{array}{c}\text { Capacidade adsortiva do } \\
\text { carvão ativado vegetal } \\
\text { (mg fluoreto/g de carvão) }\end{array}$ & $\begin{array}{c}\text { Porcentagem de } \\
\text { remoção (\%) }\end{array}$ \\
\hline A & 1,55 & 0,31 & 0,112 & 21,32 \\
\hline B & 1,60 & 0,32 & 0,116 & 18,37 \\
\hline C & 1,51 & 0,302 & 0,164 & 23,74 \\
\hline D & 1,34 & 0,268 & 0,216 & 31,28 \\
\hline
\end{tabular}

Fonte: Acervo do autor (2015).

Ao analisar as tabela 2 e 3, confirmase que os aditivos nitrato e/ou sulfato não interferem no processo de adsorção do fluoreto, portanto, baseado nessas tabelas considerou-se que os demais ânions não interferem na adsorção do ânion estudado.

Outra característica clara ao analisar as tabelas 2 e 3 é a maior eficiência do carvão de ossos calcinados, que chegou à $31,28 \%$, comparado ao carvão ativado vegetal que chegou, apenas, à 10,61\%. Desta forma, podese afirmar que a remoção do fluoreto com carvão de ossos calcinados é mais eficiente que com o carvão ativado vegetal.

Assim, a sequência deste trabalho prosseguiu com análises de soluções sem aditivos de nitrato e sulfato e com o carvão de ossos calcinados como meio adsorvente.

\subsection{Avaliação da Influência do pH.}

Os resultados da dependência do $\mathrm{pH}$ na remoção de íons fluoreto com o carvão de ossos calcinados pode ser vista na tabela.

Tabela 4: Dependência do pH na remoção de íons fluoreto com o carvão de ossos calcinados.

\begin{tabular}{|c|c|c|c|c|c|}
\hline Solução & $\mathbf{p H}$ & $\begin{array}{c}\text { Concentração } \\
\text { inicial de } \\
\text { fluoreto }(\mathbf{m g} / \mathbf{L})\end{array}$ & $\begin{array}{c}\text { Concentração } \\
\text { final de } \\
\text { fluoretos } \\
\text { (mg/L) }\end{array}$ & $\begin{array}{c}\text { Capacidade } \\
\text { adsortiva do carvão } \\
\text { ativado vegetal (mg } \\
\text { fluoreto/g de } \\
\text { carvão) }\end{array}$ & $\begin{array}{c}\text { Porcentagem } \\
\text { de remoção } \\
(\%)\end{array}$ \\
\hline $\mathrm{E}$ & 4 & 1,97 & 1,55 & 0,168 & 21,32 \\
\hline $\mathrm{F}$ & 7,3 & 1,97 & 1,72 & 0,100 & 12,7 \\
\hline $\mathrm{G}$ & 10,3 & 1,97 & 1,76 & 0,084 & 10,66 \\
\hline
\end{tabular}

Fonte: Acervo do autor (2015). 
Com os dados obtidos, confirmase que em meios ácidos a capacidade de adsorção de fluoreto em carvão de ossos calcinados é favorecida foi evidenciada. Vimos que no caso de um $\mathrm{pH}$ ácido a porcentagem de remoção foi de $21,32 \%$, já para um $\mathrm{pH}$ básico esta porcentagem cai para $10,66 \%$, ou seja, uma queda bem significante e que nos atrai a realizar os próximos testes em meio ácido.

\subsection{Avaliação da Influência da Temperatura.}

Os resultados da dependência da temperatura na remoção de íons fluoreto com o carvão de ossos calcinados encontram-se na tabela 5 .

Tabela 5: Dependência da temperatura na remoção de íons fluoreto com o carvão de ossos calcinados

\begin{tabular}{|c|c|c|c|c|}
\hline $\begin{array}{c}\text { Temperatura } \\
\left({ }^{\circ} \mathbf{C}\right)\end{array}$ & $\begin{array}{c}\text { Concentração } \\
\text { inicial de } \\
\text { fluoreto } \\
(\mathbf{m g} / \mathbf{L})\end{array}$ & $\begin{array}{c}\text { Concentração } \\
\text { final de } \\
\text { fluoretos } \\
(\mathbf{m g} / \mathbf{L})\end{array}$ & $\begin{array}{c}\text { Capacidade adsortiva } \\
\text { do carvão ativado } \\
\text { vegetal (mg fluoreto/g } \\
\text { de carvão) }\end{array}$ & $\begin{array}{c}\text { Porcentagem } \\
\text { de remoção } \\
(\%)\end{array}$ \\
\hline 20 & 1,97 & 1,55 & 0,168 & 21,32 \\
\hline 30 & 1,97 & 1,65 & 0,128 & 16,24 \\
\hline 50 & 1,97 & 1,69 & 0,112 & 14,21 \\
\hline
\end{tabular}

Fonte: Acervo do autor (2015).

Com estes resultados, tem-se, também, a confirmação que quando se aumenta a temperatura, reduz-se a capacidade adsortiva do carvão de ossos calcinados. Em temperaturas baixas a porcentagem de remoção é bem maior, cerca de 21,32\%, quando comparado à remoção em temperaturas mais altas, $14,21 \%$ a $50{ }^{\circ} \mathrm{C}$. Este fato pode ser explicado pela característica exotérmica do processo de adsorção.

\section{CONCLUSÃO}

Com estes experimentos, foi verificado que o processo de remoção de fluoretos via adsorção por carvão de ossos calcinados é bem mais eficiente que o processo de remoção com carvão ativado vegetal.

Além da conclusão quanto aos carvões, a presença de outros contaminantes não mostra um obstáculo à adsorção, sendo este fato muito positivo, já que em outros processos este fato é determinante para a não utilização da tecnologia.

Quanto ao $\mathrm{pH}$, a solução com caráter ácida se mostrou, como esperado, mais propícia à adsorção, já quando a solução é básica a eficiência do processo cai significativamente.

A última característica processual foi a tendência exotérmica da adsorção, esta conclusão pôde ser tirada porque quando se adicionou calor à mistura o potencial adsortivo foi claramente prejudicado.

\section{REFERÊNCIAS BIBLIOGRÁFICAS}

ABE, I.; IWASAKI, S.; TOKIMOTO, T.; KAWASAKI, N.; NAKAMURA, T.; TANADA, S. Adsorption of fluoride ions onto carbonaceous materials, Journal of Colloid and Interface Science, v.275, p.35-39, 2004. 
ALESSIO, K. O., BASTOS, L. F., SOARES M. F. M., COSTA A. B., ALCAYAGA, E. A. L. Desfluoretação Parcial de Águas Subterrâneas por Adsorção/Precipitação Pelo Contato em Micro colunas de Filtração. Revista Jovens Pesquisadores, Santa Cruz do Sul, v. 4, n. 3, p.53-66, 2014.

BRASIL, Ministério da Saúde. Portaria 2914, de 12 de dezembro de 2011. Estabelece os procedimentos e responsabilidades relativos ao controle e vigilância da qualidade da água para consumo humano e seu padrão de potabilidade e dá outras providências.

CHARBEL, M. Y. Estudo Para a Remoção de Fluoreto em Águas e Efluentes, Instituto de Pesquisas Energéticas e Nucleares, São Paulo, p. 1-37, 1990.

COSTA, A. B.; LOBO, E. A.; SOARES, J.; KIRST, A. Desfluoretação de Águas Subterrâneas Utilizando Filtros de Carvão Ativado de Osso, Associação Brasileira de Águas subterrâneas, p. 6070, 2013.

PICKERING, W.F., SLAVEK , J., WALLER, P. The effect of ion exchange on the solubility of fluoride compounds. Water Air Soil Pollution, 39(3-4), 323-336, 1988.

RIBEIRO, M. V. Uso de Carvão de osso Bovino na Defluoretação de Água para Uso em Abastecimento Público, Universidade Federal de Minas Gerais, Belo Horizonte, p. 14-53, 2011.
SAHU, N.K., KARIM, M.A. Fluoride incidence in natural waters in Amreli district Gujarat. Journal of Geological Society of India 33(5), 450-456, 1989.

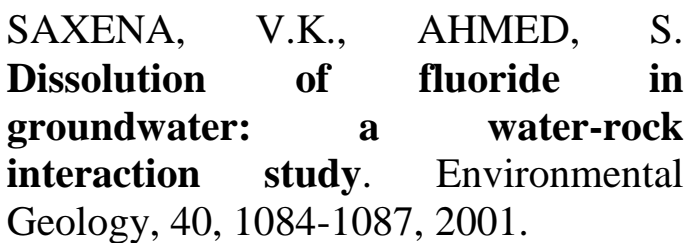

TAKENO, N. Atlas of Eh-pH diagram. Geological Survey of Japan, Open File, Report no. 419, 2005.

TCHOMGUI-KAMGA, E.; NGAMENI, E.; DARCHEN, A. Evaluation of removal efficiency of fluoride from aqueous solution using new charcoals that contain calcium com-pounds. Journal of Colloid and Interface Science, v. 346, p. 494-499, 2010.

UMLONG, I. M.; DAS, B.; DEVI, R. R.; BORAH, K.; SAIKIA, L. B.; RAUL, P. K.; BANERJEE, S.; SINGH, L. Defluoridation from aqueous solution using stone dust and activated alumina at a fixed ratio. Applied Water Science, vol. 2, n. 1, p. 29-36, 2012.

\section{AGRADECIMENTOS}

À empresa Hidro Solo Indústria e Comércio LTDA por ceder seu equipamento de colorimetria Hanna HI 83208 e os reagentes pertinentes à análise de fluoreto. 